\title{
Validity of self reported data on injury prevention behavior: lessons from observational and self reported surveys of safety belt use in the US
}

\author{
David E Nelson
}

\begin{abstract}
Objectives-To examine the validity of self reported data on safety belt use and to consider the implications for research on injury prevention behaviors.
\end{abstract}

Methods-1992 and 1993 self reported data on safety belt use were obtained from the Behavioral Risk Factor Surveillance System and observational data were obtained from the National Highway Traffic Safety Administrations for 49 states in 1992 and 50 states in 1993. The ratio of self reported to observed belt use was calculated for each state, and linear regression models were used to examine the association between the two methods.

Results-There was variation between states, but the overall median ratio of self reported to observed safety belt use was 1.05 in 1992 (interdecile range 0.87-1.36) and 1.02 in 1993 (interdecile range $0 \cdot 87-1 \cdot 31)$. Self reports were substantially higher in southern states and in states with the lowest levels of observed use. Linear regression models indicated a moderately strong association between state estimates using both methods. For every percentage point increase in self reported data in 1993, observed safety belt use increased by 0.95 percentage point.

Conclusions-In the aggregate, self reported estimates were only $2 \%$ to $5 \%$ higher than observed estimates. This is a substantial improvement from previous studies. This is probably due to the increased prevalence of safety belt use and the declining effects of social desirability on self reported use. In general, the validity of self reported estimates of socially desirable injury prevention behaviors will be higher when the actual prevalence of the behavior is higher, but lower when this is not true.

(Injury Prevention 1996; 2: 67-69)

Office of Surveillance and Analysis, Centers for Disease Control and Prevention, 4770 Buford Highway NE, Mailstop K-30, Mailstop K-30 30341-3724, USA

Correspondence to: Dr Nelson. their children. ${ }^{3}$ The main reason for overreporting of certain behaviors is social desirability. ${ }^{45}$ The validity of self reported data on injury behavior is of more than academic interest. Well designed observational studies are expensive, ${ }^{6}$ whereas telephone and self administered surveys are much less expensive and provide more information.

This problem has been examined most thoroughly for safety belt use, where it has been known for more than 25 years that self reported use exceeds observed use. ${ }^{6}$ Studies conducted in 1987 and 1988 compared estimates of self reported safety belt use from several US states (11 and 15 states) with estimates from state and local observational surveys. ${ }^{17}$ Self reports averaged eight percentage points higher when safety belt use was defined as 'always' using seat belts, ${ }^{7}$ and 21.5 to 27 percentage points higher when use was defined as 'always' or 'nearly always' using them. ${ }^{17}$ It has been suggested that self reports generally overestimate observed safety belt use by $40 \%{ }^{6}$

Since 1988, an increasing number of US states have conducted telephone surveys of health risk behaviors and by 1993 , annual state self reported and observational estimates of safety belt use were available for all but one state. Because observed use of safety belts has greatly increased in the US over the past 10 years ${ }^{8}$ this provided an opportunity to reexamine the validity of self reported data and to consider the general implications for self reported injury prevention behavior data obtained from adolescents, parents, and other adults.

\section{Methods}

State data on safety belt use from observational surveys conducted in 1992 and 1993 were obtained from the US National Highway Traffic Safety Administration (NHTSA) (unpublished data, NHTSA, 1993 and 1994). About $40 \%$ of states use probability sampling techniques to select locations and times for these observations. These produce statistically valid estimates with a maximum standard error of $5 \%$. Generally, data were obtained on observed use of shoulder belts for drivers and right front seat passengers during daylight hours. ${ }^{9}$ NHTSA provided information on the presence, type, and date of implementation of state safety belt laws (if any). ${ }^{10}$ 
Self reported safety belt use data were obtained from 49 states in 1992 and 50 states in 1993 from the Behavioral Risk Factor Surveillance System (BRFSS). ${ }^{11}$ Briefly, state health departments conduct monthly telephone surveys of health risk behaviors among randomly selected persons aged 18 and older. For the two year period, the average annual sample size was 2008 per state and the median response rate was $71.0 \%$. In all states, BRFSS respondents were asked: 'How often do you use seat belts when you drive or ride in a car?' Possible responses, which were read to responders, include always, nearly always, sometimes, seldom, or never. Only persons who reported that they 'always' use seat belts were classified as safety belt users.

Statistical analyses were conducted using SPSS for Windows; all data were analyzed separately by year. BRFSS estimates were weighted to produce statewide estimates. To compare differences between observation and self reports, I calculated the ratio of self reported to observed estimates of use in each state and the median value and interdecile range (10th-90th centile) (to examine the effect of outliers on the range). $p$ Values based on the Kruskal-Wallis and Mann-Whitney $U$ tests were used to compare median ratio values by geographic region, ${ }^{12}$ by type of safety belt law (primary, secondary, or none), observed safety belt use (in quartiles), and the use of probability sampling in the observational surveys (yes or no). Linear regression models were created to determine the association between observed and self reported estimates, and the ratio of the estimates with length of time safety belt laws had been in force. The fit of these models was measured using the $r^{2}$ statistic.

\section{Results}

The median ratio of self reported to observed belt use among states was 1.05 in 1992 and 1.02 in 1993, although there was substantial variability by state. The interdecile range (10th-90th centile) indicated that self reported use ranged from $13 \%$ lower than observed use for both years, to $36 \%$ higher in 1992, and $31 \%$ higher in 1993.

Median ratios for self reported to observed prevalence estimates for state safety belt use, overall and by region and quartiles of observed use, 1992 and 1993

\begin{tabular}{|c|c|c|}
\hline & $1992 \star$ & $1993^{\star}$ \\
\hline Overall & $1.05(0.60-1.83)$ & $1.02(0.74-1.84)$ \\
\hline $\begin{array}{l}\text { Interdecile range } \\
\text { (10th-90th centile) }\end{array}$ & $0 \cdot 87-1 \cdot 36$ & $0 \cdot 87-1 \cdot 31$ \\
\hline \multicolumn{3}{|l|}{ Regiont } \\
\hline Northeast & $1.07(0.87-1.80)$ & $1.00(0.87-1.38)$ \\
\hline South & $1.17(0.98-1.83)$ & $1.09(0.89-1.84)$ \\
\hline Midwest & $0.98(0.60-1.23)$ & $0.99(0.74-1.16)$ \\
\hline West & $1.04(0.68-1.29)$ & $1.01(0.79-1.22)$ \\
\hline \multicolumn{3}{|l|}{ Observed safety belt use ${ }_{+}^{+}$} \\
\hline Lowest quartile & $1.28(0.60-1.83)$ & $1.18(0.96-1.84)$ \\
\hline Second quartile & $1.14(0.93-1.29)$ & $1.04(0.87-1.31)$ \\
\hline Third quartile & $1.03(0.87-1.19)$ & $0.96(0.86-1.10)$ \\
\hline Highest quartile & $1.01(0.68-1.11)$ & $0.99(0.74-1 \cdot 10)$ \\
\hline
\end{tabular}

Note: median state estimates were $62^{\circ}{ }_{0}$ (range $25^{\circ}{ }_{0}-89^{\circ}{ }_{0}$ ) from self reports and $58^{\circ}$, (range $25^{\circ}{ }_{0}-84^{\circ}$ ) from observation surveys in 1992, and $63.5 \%$ (range $25^{\circ}{ }_{0}-90^{\circ}$ ) for self reports and $62^{\circ}$ (range $25^{\circ}-84^{\circ}$ ) for observation surveys in 1993 $\star$ Numbers in parentheses indicate the total range among states. $+p<0.01$ for differences by region in 1992 and $p=0.02$ for differences in 1993. $+p<0.01$ for differences by quartile of observed safety belt use for both years.
The differences between BRFSS and observational estimates varied by region, with ratios higher in the south than in other regions (table). The differences between the two methods were greatest in states in the lowest quartile of observed safety belt use. (Observed use was generally lowest in southern states; thus, there was substantial overlap when comparing ratios by region and by quartile of observed use.) For both years, there were no differences in the ratios of self reported and observational data when compared by the use of probability samples for observational surveys, presence of any safety belt law, type of law, or number of years the laws had been in effect (data not shown).

For 1992, the linear regression model fit these data relatively well $\left(r^{2}=0.59\right)$. Thus, for every percentage point increase in self reported used, there was a predicted increase of 0.84 percentage points in observed belt use (fig 1). The fit of the model was even better in 1993 $\left(r^{2}=0.66\right)$ resulting in a predicted increase of 0.95 percentage points for every percentage point increase in self reported used (fig 2)

\section{Discussion}

Although there was considerable variation among states, the overall association between self reported and observational estimates of
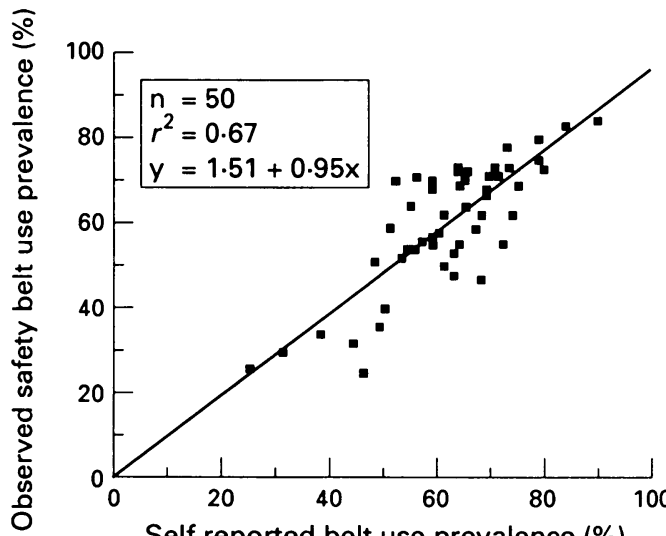

Self reported belt use prevalence (\%)

Figure 1 Association between observed and self reported state estimates of safety belt use, 1992.

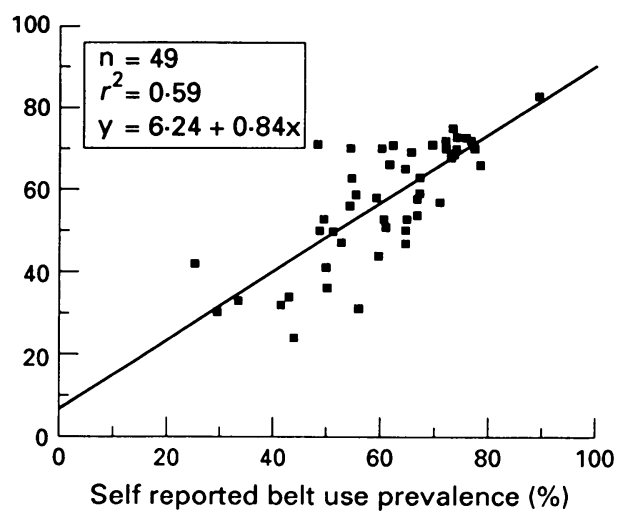

Figure 2 Association between observed and self reported state estimates of safety belt use, 1993. 
state safety belt use has improved substantially since the 1980s. By 1993, self reports were only $2 \%$ higher than observed belt use when data were aggregated across all states. The association between the two methods was greater than that reported in $1987 .{ }^{7}$ However, because of the substantial within state variation between the two methods, data from state specific observational surveys are still valuable for estimating actual safety belt use.

The lack of an association between safety belt laws and differences between self reported $v$ observed belt use in this study confirms findings from Michigan. ${ }^{6}$ Streff and Wagenaar suggested that this lack of an association may be because persons who previously overreported safety belt use also were more likely to become belt users after safety belt laws were enacted. ${ }^{6}$

There are limitations to this study. Observational surveys and BRFSS are independent systems, so except by chance, data are not obtained on the same individuals. Moreover observational surveys probably overestimate actual use, as they are conducted during daylight hours, which are not necessarily the times when persons at increased risk for not wearing safety belts are traveling in motor vehicles. ${ }^{13}$ Observational data also include some data on persons under 18 years of age whereas BRFSS data includes only persons aged 18 years or older.

In many states observation sites are not selected at random, hence, these data are not necessarily representative of the state. In most states these data are also collected only during one time period. In contrast, BRFSS data are obtained from random samples, produce representative estimates, are collected monthly, and averaged across the year. ${ }^{11}$

BRFSS excludes persons in households without telephones. This may result in overestimates of reported belt use because persons with lower incomes are less likely to have telephones ${ }^{14}$ and to use safety belts. ${ }^{15}$ But the effect is likely to be small, as $95 \%$ of US households have telephones. ${ }^{14}$ Defining safety belt users as only those repondents who report 'always' using belts - the most conservative definition - undoubtedly results in closer agreement between the two methods. Previous research has consistently demonstrated that when broader definitions are used (for example, 'nearly always', 'nine out of the last 10 trips'), self reports are substantially higher than observed use. $^{6}$

\section{Conclusions and implications}

What accounts for the improved association between self reported and observation data on safety belt use? One possibility is chance, but this is unlikely, as the findings are consistent across both years. Another reason may be the inevitable convergence as the prevalence of safety belt use increases.

The reduced impact of social desirability also probably plays a part. ${ }^{45}$ Telephone survey estimates were substantially higher than observational estimates in states where observed belt use was the lowest, but were similar in states where observed use was highest. Social desirability may be operating to a greater extent when observed belt use is low, but its impact decreases as actual belt use increases.

Based on this study and on previous research, certain conclusions about safety belt use and other self reported injury prevention behaviors among adolescents and adults seem warranted. When using graded response categories to survey questions, such as a Likert scale (and for measuring many types of behavior, this is the preferred approach), ${ }^{16}$ only persons who report that they 'always' practice a certain behavior should be considered to do so. Social desirability appears to strongly influence reponses to this type of survey question, with fewer people being willing to report that they 'never' practice behaviors that are highly socially approved. Selecting only persons who 'always' practice a given behavior substantially diminishes social desirability effects. Despite defining safety belt use as 'always use' for self reports, there was still more overreporting in states where observed safety belt use was lowest. This suggests that the validity of self reported prevalence estimates of most socially desirable injury prevention behaviors will be high when the true prevalence of the actual behavior is common, but that this validity will be low when this is not the case.

I would like to thank Jeff Michael, Ed D, Julie Russell, PhD, Deborah Holtzman, PhD, Richard Rubinson, $\mathrm{PhD}$, and Lanelle Henderson for their assistance.

1 Robertson LS. The validity of self-reported behavioral risk factors: seatbelt and alcohol use. F Trauma 1992; 32: factors:

2 Smith PF, Remington PL, Williamson DF, et al. A comparison of alcohol sales data with survey data on selfreported alcohol use in 21 states. Am f Public Health 1990 80: 309-12.

3 Stulginskas JV, Verreault R, Pless IB. A comparison of observed and reported restraint use by children and adults. Accid Anal Prev 1985; 17: 381-6.

4 Rouse BA, Kozel NJ, Richards LG, eds. Self-report methods of estimating drug use: meeting current challenges to validity. Rockville, Maryland: Alcohol, Drug Abuse, and validity. Rockvill Mintration, 1985. (NIDA Research Monograph No 57.)

5 Sudman S, Bradburn NM. Response effects in surveys. Chicago, IL: Aldine, 1974.

6 Chicago, IL: Aldine, 1974. Estimating seat belt use with self-report measures. Accid Anal Prev 1989; 6: 509-16.

7 Centers for Disease Control. Comparison of observed and self-reported seat belt use rates - United States. $M M W R$ 1988; 37: 549-51.

8 McGinnis JM, Lee PR. Healthy people 2000 at mid decade. JAMA 1995; 273: 1123-9.

9 National Highway Traffic Safety Administration. Guidelines for state observational surveys of safety belt and motorcycle helmet use. Washington, DC: United States Federal Register, Vol 57, No 125, 1992: 28899-904 (January 29).

10 National Highway Traffic Safety Administration. Key provisions of safety belt use laws. Washington, DC

11 Frazier EL, Franks AI, Sanderson LM. Using behavioral risk factor surveillance data. Using chronic disease data: $a$ risk factor surveillance data. Using chronic disease data: a
handbook for public health practitioners. Atlanta, GA: handbook for public health practitioners. Atlanta,

12 US Bureau of the Census. Statistical abstract of the United States: 1994. Washington, DC: US Bureau of the Census, States:
1994.

13 Preusser DF, Williams AF, Lund AK. Characteristics of belted and unbelted drivers. Accid Anal Prev 1991; 23: 475-82.

14 US Bureau of the Census. Statistical brief: phoneless in America. Washington, DC: US Department of Commerce, Economics and Statistics Administration, 1994. (Publication No SB/94-16.)

15 Lund AK. Voluntary seat belt use among US drivers: geographic, socioeconomic and demographic variation. Accid Anal Prev 1986; 18: 43-50.

16 Nunnally JC. Psychometric theory. New York: McGrawHill, 1978. 